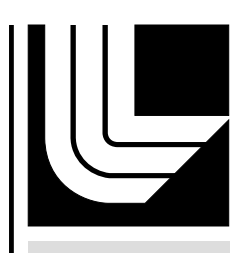

LA W REN CE LIVERMORE N A TIONAL LABORATORY

\title{
SIZE EFFECT AND CYLINDER TEST ON SEVERAL COMMERCIAL EXPLOSIVES
}

P. C. Souers, L. Lauderbach, K. Moua, R. Garza

June 3, 2011

APC Shock Compression

Chicago, IL, United States

June 26, 2011 through July 1, 2011 
This document was prepared as an account of work sponsored by an agency of the United States government. Neither the United States government nor Lawrence Livermore National Security, LLC, nor any of their employees makes any warranty, expressed or implied, or assumes any legal liability or responsibility for the accuracy, completeness, or usefulness of any information, apparatus, product, or process disclosed, or represents that its use would not infringe privately owned rights. Reference herein to any specific commercial product, process, or service by trade name, trademark, manufacturer, or otherwise does not necessarily constitute or imply its endorsement, recommendation, or favoring by the United States government or Lawrence Livermore National Security, LLC. The views and opinions of authors expressed herein do not necessarily state or reflect those of the United States government or Lawrence Livermore National Security, LLC, and shall not be used for advertising or product endorsement purposes. 


\title{
SIZE EFFECT AND CYLINDER TEST ON SEVERAL COMMERCIAL EXPLOSIVES
}

\author{
P. C. Souers, L. Lauderbach, K. Moua and R. Garza \\ Energetic Materials Center, L-282, Lawrence Livermore National Laboratory, Livermore, CA 94550 USA
}

\begin{abstract}
The size (diameter) effect and the Cylinder test results for Kinepak (ammonium nitrate/nitromethane), Red Dot and Bullseye shotgun powders, Semtex 1, Semtex H and urea nitrate will be presented. Cylinder test data appears normal despite faster sound speeds in the copper wall. Most explosives come to steady state in the Cylinder test as expected, but Kinepak shows a steadily increasing wall velocity with distance down the cylinder. Kinepak appears to have a late-time reaction about one hundred times slower than the initial detonation.
\end{abstract}

Keywords: size effect, diameter effect, detonation velocity, detonation energy, Cylinder test PACS: 82.33.Vx, 82.40.Fp

\section{INTRODUCTION}

The size (diameter) effect for detonation velocity [1] and the copper-wall Cylinder test for detonation energy density [2-4] are basic measures of detonation.

Kinepak is a commercial mixture nominally of $\mathrm{AN} 79 \mathrm{wt} \% / \mathrm{NM} 21$. The old version contained $2.9 \mathrm{wt} \%$ glass microballoons and the new (from shot 750 on) $4.0 \%$. The old AN was $30-150 \mu \mathrm{m}$ with a peak at $60 \mu \mathrm{m}$ and the new is coarser. The liquid is added just before shooting and the absorption appears uniform.

Semtex 1A is PETN 83.5, semtexoil 12.4, and rubber 4.1. Semtex $\mathrm{H}$ or $1 \mathrm{H}$ is RDX 60.5, PETN 25.0, semtexoil 11.6, rubber (styrene/butadiene) 2.9. Red Dot is a shotgun powder made up of NG 20, NC-13.2 77.5, diphenylamine 0.7 , carbon black 0.5 , potassium nitrate 0.3 , graphite 0.3 , acetone/ethanol 0.5 , water 0.2 . Bullseye is a shotgun powder made of NC 40, NC-13.2 58, ethyl centralite 0.7, potassium sulfate 0.3 , graphite 0.3 , acetone/ethanol 0.5 , and water 0.2 .

\section{EXPERIMENTAL PROCEDURE}

The detonation velocities were measured with shorting pin rings. The standard deviation comes from comparing two rings with 6 pins each.

The Cylinder Tests measure wall velocity with PDV (photon Doppler shift or heterodyne) [5]. A heavy aluminum rack is now used to hold the probe angles constant. In Table 2, all wall velocities are at scaled 1-inch diameters for displacements of $6,12.5$ and $19 \mathrm{~mm}$. These correspond to relative volumes in the cylinder of 2.4, 4.4 and 7.0 [4].

\section{RESULTS AND DISCUSSION}

Table 1 lists the size effect data for three explosives. The average detonation rate, $v$, is inversely proportional to the slope by way of

$$
v \approx \frac{-D^{2}}{d U_{s} / d\left(1 / R_{o}\right)},
$$

where $U_{S}$ is the detonation velocity at radius $R_{0}$ and $\mathrm{D}$ is the detonation velocity at infinite radius. The Kinepak rate is $4.0 \mu \mathrm{s}^{-1}$ in metal and $1.2 \mu \mathrm{s}^{-1}$ in plastic, and the confined Red Dot rate is $4.2 \mu \mathrm{s}^{-1}$. These are low, ANFO-like, non-ideal values. The Semtex rate cannot be quanitified, but it is clearly large, perhaps $200 \mu \mathrm{s}^{-1}$.

Table 2 lists the Cylinder test results. Today's Cylinder test analysis calculates the detonation energy density while accounting for the angle of the PDV probe [4], with the energy varying as the cosine of the probe angle. Table 2 lists results for Semtex $1 \mathrm{H}$ with six probes at the same distance down the cylinder but with probe 
TABLE 1. Size (diameter) effect data.

\begin{tabular}{|c|c|c|c|c|c|c|c|}
\hline $\begin{array}{c}\text { Density, } \\
\text { g/cc }\end{array}$ & $\begin{array}{c}\text { Radius, } \\
\text { mm }\end{array}$ & $\begin{array}{l}\text { Detvel, } \\
\mathrm{mm} / \mu \mathrm{s}\end{array}$ & $\begin{array}{l}\text { stdev, } \\
\mathrm{mm} / \mu \mathrm{s}\end{array}$ & $\begin{array}{c}\text { Wall } \\
\text { material }\end{array}$ & $\begin{array}{c}\text { Wall, } \\
\text { mm }\end{array}$ & $\begin{array}{c}\text { Length, } \\
\text { mm }\end{array}$ & $\begin{array}{l}\text { Shot } \\
\text { No. }\end{array}$ \\
\hline \multicolumn{8}{|l|}{ Kinepak } \\
\hline 1.25 & 25.85 & 5.46 & 0.021 & steel & 2.83 & 508 & 666 \\
\hline 1.24 & 25.38 & 5.29 & 0.008 & steel & 5.22 & 458 & 851 \\
\hline 1.20 & 12.71 & 5.13 & 0.014 & copper & 2.61 & 305 & 657 \\
\hline 1.16 & 6.56 & 4.62 & 0.046 & steel & 2.90 & 254 & 665 \\
\hline 1.05 & 6.35 & 3.92 & 0.014 & copper & 1.36 & 152 & 750 \\
\hline 1.25 & 4.76 & 4.00 & 0.034 & steel & 1.54 & 257 & 668 \\
\hline 1.17 & 3.98 & 3.17 & 0.028 & steel & 2.37 & 254 & 681 \\
\hline 1.24 & 3.97 & 4.15 & 0.054 & copper & 3.18 & 153 & 792 \\
\hline 1.12 & 3.12 & 2.49 & 0.117 & steel & 1.70 & 254 & 670 \\
\hline 1.38 & 3.09 & 1.87 & & steel & 3.27 & 254 & 669 \\
\hline 1.17 & 2.61 & 2.94 & 0.052 & steel & 3.72 & 254 & 703 \\
\hline 1.17 & 6.42 & 4.12 & 0.242 & steel & 9.46 & 254 & 679 \\
\hline 1.31 & 6.38 & 4.66 & 0.132 & steel & 19.00 & 253 & 672 \\
\hline 1.22 & 3.20 & 3.53 & 0.226 & steel & 9.49 & 254 & 674 \\
\hline 1.33 & 2.80 & 1.18 & & steel & 9.90 & 254 & 678 \\
\hline 1.23 & 2.38 & 0.62 & & steel & 10.31 & 254 & 677 \\
\hline 1.23 & 25.40 & 4.61 & 0.010 & Lucite & 3.20 & 509 & 671 \\
\hline 1.20 & 15.94 & 3.99 & 0.014 & Lucite & 3.12 & 509 & 661 \\
\hline 1.14 & 12.73 & 3.37 & 0.010 & Lucite & 0.50 & 254 & 675 \\
\hline 1.20 & 11.17 & 3.23 & 0.015 & Lucite & 1.68 & 257 & 660 \\
\hline 1.20 & 8.03 & 2.68 & 0.016 & Lucite & 1.57 & 254 & 662 \\
\hline 1.20 & 6.39 & fail & & Lucite & 1.54 & 254 & 664 \\
\hline \multicolumn{8}{|l|}{ Red Dot } \\
\hline 0.53 & 25.39 & 3.641 & 3.64 & steel & 6.37 & 457 & 821 \\
\hline 0.52 & 12.71 & 3.468 & 3.35 & copper & 2.61 & 305 & 651 \\
\hline 0.49 & 12.71 & 3.282 & 3.36 & copper & 2.61 & 304 & 653 \\
\hline 0.52 & 6.43 & 3.248 & 3.12 & steel & 1.56 & 254 & 715 \\
\hline 0.52 & 3.98 & 2.827 & 2.70 & steel & 0.83 & 153 & 828 \\
\hline 0.49 & 3.10 & 2.562 & 2.60 & steel & 1.64 & 254 & 717 \\
\hline 0.47 & 2.29 & 2.480 & 2.64 & steel & 1.71 & 152 & 820 \\
\hline \multicolumn{8}{|l|}{ Semtex 1A } \\
\hline 1.451 & 13.54 & 7.575 & 0.041 & steel & 2.34 & 252 & 815 \\
\hline 1.395 & 12.71 & 7.489 & 0.054 & copper & 2.61 & 305 & 647 \\
\hline 1.446 & 9.97 & 7.648 & 0.093 & steel & 2.81 & 229 & 832 \\
\hline 1.423 & 6.44 & 7.502 & 0.050 & steel & 1.55 & 254 & 718 \\
\hline 1.421 & 6.31 & 7.580 & 0.045 & steel & 1.65 & 153 & 831 \\
\hline 1.420 & 3.10 & 7.604 & 0.050 & steel & 1.62 & 254 & 719 \\
\hline
\end{tabular}

angles from 5 to $10^{\circ}$. The velocities are the same within error, showing that the effect of angle error is indeed small.

With many probes with modern accuracy, we may check two other issues regarding the Cylinder test. One is whether anything unusual occurs because the detonation velocity of the explosive is less than the sound speed in the copper wall. Our best example is the pure component urea nitrate, which was measured at 0.746 and $0.944 \mathrm{~g} / \mathrm{cc}$ with a $25.4 \mathrm{~mm}$ diameter and gave detonation velocities of 3.28 and 4.41 $\mathrm{mm} / \mu \mathrm{s}$. As shown in Figure 1, both came to the 
TABLE 2. Cylinder test data at the three standard wall displacements: $6,12.5$ and $19 \mathrm{~mm}$.

\begin{tabular}{|c|c|c|c|c|c|c|c|c|c|}
\hline Explosive & $\begin{array}{c}\text { radius, } \\
\text { mm }\end{array}$ & $\begin{array}{c}\text { thick, } \\
\text { mm }\end{array}$ & $\begin{array}{c}\text { probe } \\
\text { no. }\end{array}$ & $\begin{array}{c}\text { angle, } \\
\text { deg }\end{array}$ & $\begin{array}{c}\text { view, } \\
\text { mm }\end{array}$ & $\begin{array}{c}\text { length, } \\
\text { mm }\end{array}$ & $\begin{array}{c}\text { wall } \\
6\end{array}$ & $\begin{array}{c}\text { velocity, } \\
12.5\end{array}$ & $\frac{\mathrm{mm} / \mu \mathrm{s}}{19}$ \\
\hline Semtex H & 12.706 & 2.599 & 1 & 5 & 240 & 305 & 1.260 & 1.380 & 1.435 \\
\hline$\# 814$ & & & 2 & 5 & 240 & 305 & 1.276 & 1.386 & 1.442 \\
\hline $1.527 \mathrm{~g} / \mathrm{cc}$ & & & 3 & 7 & 240 & 305 & 1.268 & 1.397 & 1.450 \\
\hline \multirow[t]{3}{*}{$7.88 \mathrm{~mm} / \mu \mathrm{s}$} & & & 4 & 7 & 240 & 305 & 1.249 & 1.373 & 1.428 \\
\hline & & & 5 & 10 & 240 & 305 & 1.272 & 1.395 & 1.448 \\
\hline & & & 6 & 10 & 240 & 305 & 1.250 & 1.366 & 1.426 \\
\hline Bulleye & 25.382 & 5.225 & 1 & 7 & 211 & 458 & 0.662 & 0.765 & \\
\hline \#849 & & & 2 & 7 & 263 & 458 & 0.672 & 0.780 & 0.838 \\
\hline $0.703 \mathrm{~g} / \mathrm{cc}$ & & & 3 & 7 & 314 & 458 & 0.677 & 0.780 & 0.831 \\
\hline $4.35 \mathrm{~mm} / \mu \mathrm{s}$ & & & 4 & 7 & 364 & 458 & 0.671 & 0.776 & \\
\hline Kinepak & 25.384 & 5.216 & 1 & 7 & 211 & 458 & 0.857 & 0.983 & 1.003 \\
\hline$\# 851$ & & & 2 & 7 & 262 & 458 & 0.878 & 0.980 & 1.029 \\
\hline $1.237 \mathrm{~g} / \mathrm{cc}$ & & & 3 & 7 & 314 & 458 & 0.914 & 1.030 & 1.078 \\
\hline $5.29 \mathrm{~mm} / \mu \mathrm{s}$ & & & 4 & 7 & 364 & 458 & 0.980 & 1.089 & 1.134 \\
\hline Red Dot & 25.382 & 5.225 & 1 & 7 & 211 & 458 & 0.512 & 0.594 & 0.630 \\
\hline \#850 & & & 2 & 7 & 262 & 458 & 0.524 & 0.610 & 0.655 \\
\hline $0.529 \mathrm{~g} / \mathrm{cc}$ & & & 3 & 7 & 313 & 458 & 0.532 & 0.626 & 0.669 \\
\hline $4.35 \mathrm{~mm} / \mu \mathrm{s}$ & & & 4 & 7 & 364 & 458 & 0.535 & 0.620 & 0.660 \\
\hline
\end{tabular}

expected steady state conditions despite the probable run-ahead in the copper wall.

The second issue is whether the Cylinder test really comes to steady state in the length allowed. Previously, we measured only a single value $72 \%$ of the way down the tube. We now find that wall velocities suitable for conversion to energy densities may be measured from 46 to $87 \%$ of the way down the tube. Figure 2 shows the results for Red Dot, and steady state appears achieved by the second probe. The Bulleye appears to have reached steady state by the first probe.

Figure 3 shows the results for Kinepak and the curves rise steadily as the detonation progresses down the cylinder. This is evidence of a second slower reaction.

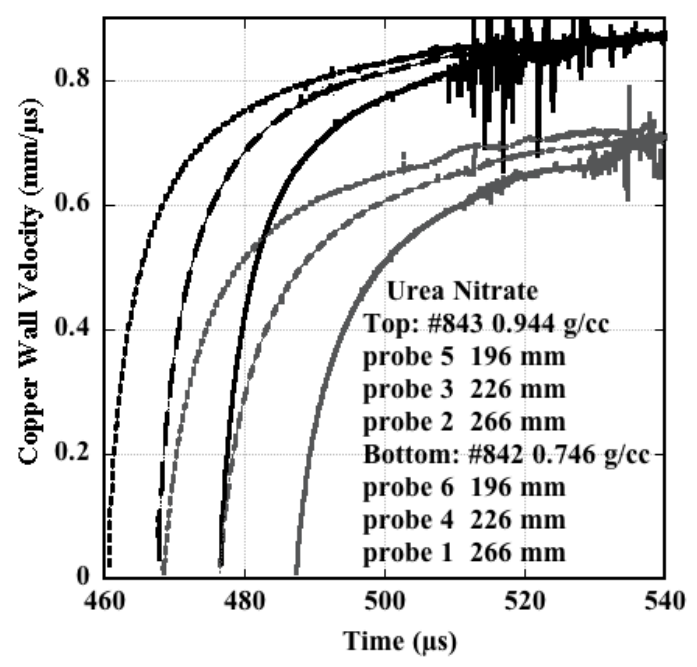

Figure 1. Wall velocities of urea nitrate at two densities, showing normal Cylinder behavior. 


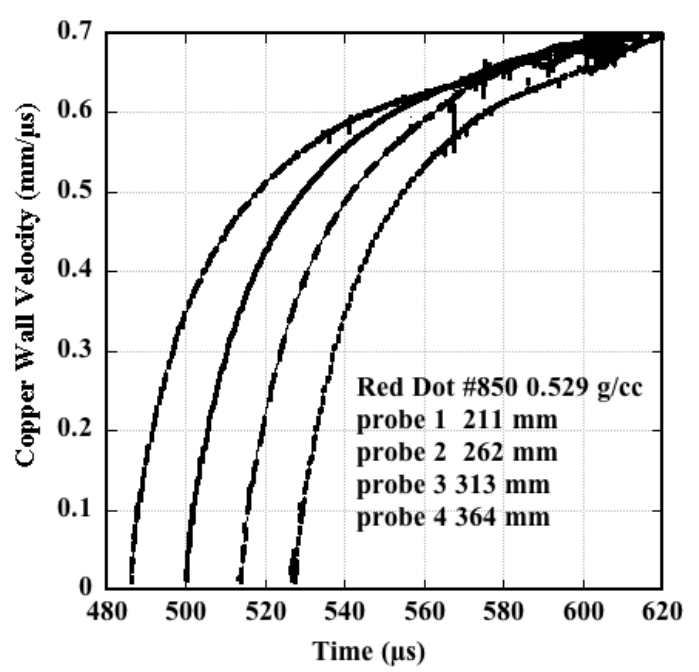

Figure 2. Cylinder test for Red Dot showing steady state by the second probe.

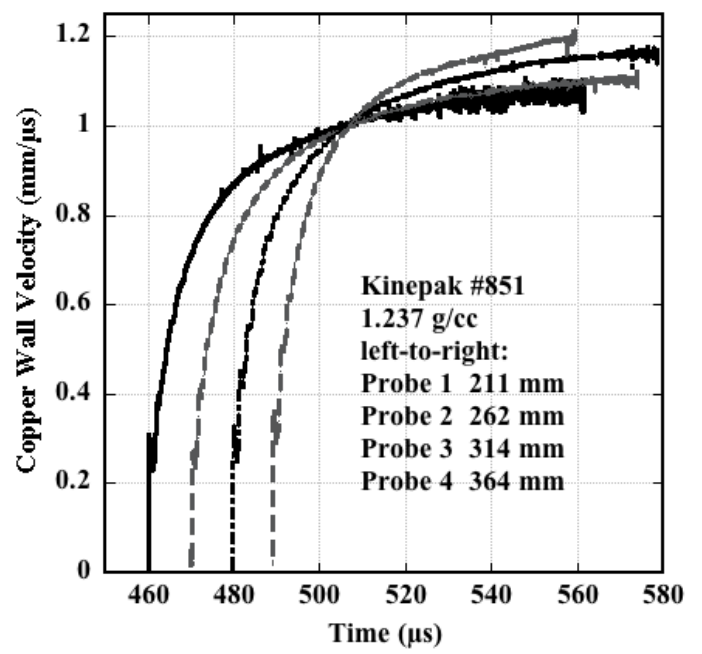

Figure 3. Cylinder test for Kinepak showing continued reaction down the cylinder.

We next convert wall velocities to detonation energy densities and plot them as a function of the detonation front time down the tube in Figure 4 [3]. The curves are at the three standard relative volumes that go with the scaled displacements in Table 2. It is difficult to judge the later reaction because it is not leveling off but appears to be increasing. We also plot the calculated points using CHEETAH V6, and the final measurements have reached these values.

The times in Figure 4 suggest a rate of perhaps $0.02 \mu \mathrm{s}^{-1}$, which is one hundred times slower than the primary rate. This would require a two-rate reactive flow model and explains why one one-rate model was inadequate.

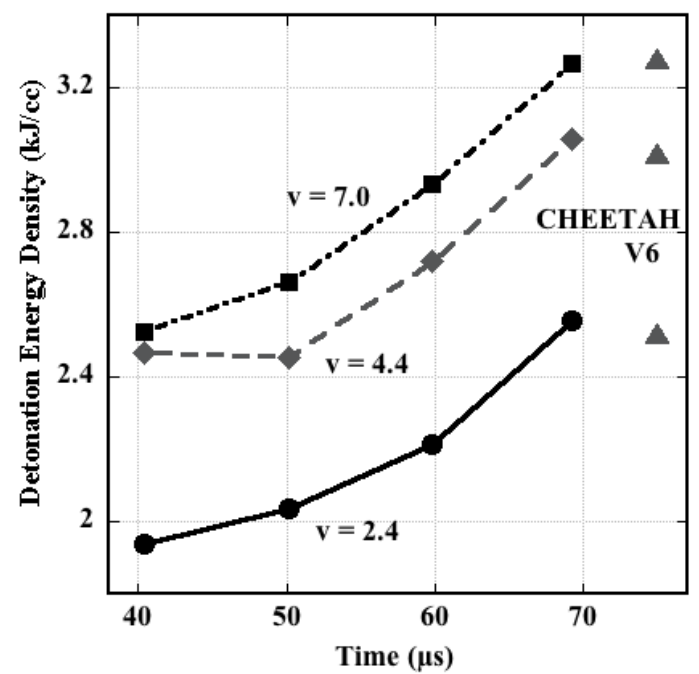

Figure 4. Detonation energy densities for Kinepak at the three standard Cylinder test relative volumes.

\section{ACKNOWLEDGMENTS}

This work performed under the auspices of the U.S. Department of Energy by Lawrence Livermore National Laboratory under Contract DE-AC52-07NA27344.

\section{REFERENCES}

1. P. Clark Souers, Steve Anderson, Estella McGuire, Michael J. Murphy, and Peter Vitello, "Reactive Flow and the Size Effect," Propellants, Explosives, Pyrotechnics, 26, 26-32, 2001.

2. P. C. Souers and J. W. Kury, "Comparison of Cylinder Data and Code Calculations for Homogeneous Explosives," Propellants, Explosives, Pyrotechnics, 18, 175-183, 1993.

3. John E. Reaugh and P. Clark Souers, "A Constant-Density Gurney Approach to the Cylinder Test," Propellants, Explosives, Pyrotechnics, 29 [2], 124-128, 2004.

4. P. C. Souers, Raul Garza, Howard Hornig, Lisa Lauderbach, Cinda Owens and Peter Vitello, "Metal Angle Correction in the Cylinder Test," Propellants, Explosives, Pyrotechnics, 36 [1], 9-15, 2011.

5. O. T. Strand, D. R. Goosman, C. Martinez and T. L. Whitworth, "Compact System for High-Speed Velocimetry using Heterodyne Techniques," Rev. Sci. Instr., 2006, 77, 083108. 